\title{
Population Substructure and Patterns of Quantitative Variation among the Gollas of Southern Andhra Pradesh, India
}

\author{
B. MOHAN REDDY, ${ }^{1}$ ALEXA PFEFFER, ${ }^{2}$ MICHAEL H. CRAWFORD, ${ }^{2}$ AND BANRIDA \\ T. LANGSTIEH ${ }^{1}$
}

\begin{abstract}
Population substructure and biological differentiation was studied among the Golla, a pastoral caste living in the southern areas of Andhra Pradesh (AP) in India, using 11 anthropometric measurements and 20 quantitative dermatoglyphic variables. The data were collected from a sample of 334 adult males drawn from 30 villages distributed in the Chittoor district of AP, who belonged to 8 endogamous subunits of the same caste. Multiple discriminant analysis of the anthropometrics suggests a highly significant degree of discrimination that is consistent with the microgeographic variations of the groups. In contrast, in different sets of dermatoglyphs discrimination is low and generally inconsistent with both the geographic and ethnohistorical affiliations of the groups. These findings are reflected in the $F_{S T}$ value for anthropometry, which is more than double the value of dermatoglyphs. The patterns of gene flow as inferred through the regression of phenotypic variance on the distance of groups from the centroid is not generally consistent with the known backgrounds in the case of either dermatoglyphs or anthropometry. It is concluded that at the level of caste substructure representing the lowest level of population hierarchy, the quantitative variables examined here may not portray a complete picture of the historical process of subdivision. The results of this study are not in congruence with those based on another study of 13 short tandem repeat loci on the same set of populations (Reddy et al. 2001), which may provide better insights into the population structure and history of subdivision that are consistent with the known ethnohistorical backgrounds of the populations.
\end{abstract}

India offers immense scope and a variety of situations to study the processes of population subdivision and their microevolutionary significance. India's population structure is remarkable in that the population is divided into a large number of strictly defined endogamous castes, tribes, and religious groups. However, most unique and fundamental to the Indian population structure is the existence

\footnotetext{
${ }^{1}$ Anthropology and Human Genetics Unit, Indian Statistical Institute, Calcutta, India.

${ }^{2}$ Laboratory of Biological Anthropology, Department of Anthropology, University of Kansas, Lawrence,
} KS.

Human Biology, April 2001, v. 73, no. 2, pp. 291-306.

Copyright (C 2001 Wayne State University Press, Detroit, Michigan 48201-1309

KEY WORDS: CASTE SUBSTRUCTURE, BREEDING ISOLATES, SHORT EVOLUTIONARY HISTORY, ANTHROPOMETRY, QUANTITATIVE DERMATOGLYPHICS, R-MATRIX ANALYSIS, GENE FLOW, DIFFERENTIATION 
of endogamous subcastes within these castes, in any particular region or linguistic area. These subgroups are usually characterized by a high degree of isolation, small effective population size, and a high degree of inbreeding. These conditions are conducive for the process of rapid genetic microdifferentiation. There are indications that, in most cases, these subcastes might have evolved from the common parental stock through different fissioning events (Basu 1969; Malhotra 1978a, 1978b, 1979; Reddy 1982; Reddy and Gadgil 1999). However, given that the caste system in India is only two to three thousand years old, the evolutionary history of these populations may be considered relatively short.

The traditional structure of Indian populations is currently facing disintegration as a result of urbanization and increasing communication, and there is a growing trend of acceptance of marriages between subcastes. Therefore, there is a pressing need to understand this traditional population structure and study its role in shaping human biological diversity in India. In the past, many attempts have been made to understand the process of microdifferentiation among subdivided populations using traditional genetic markers (blood groups, red cell enzymes, and serum proteins) and other biological variables (Karve and Malhotra 1968; Basu 1969; Malhotra 1978a, 1978b; Malhotra et al. 1978; Reddy and Chopra 1999; Reddy et al. 1987, 1989, 1995, 2000; Murty et al. 1993; Sirajuddin et al. 1994; Ramana et al. 1996). However, with the realization that molecular genetic markers help answer questions pertaining to microevolution more precisely, and particularly after the development of rapid screening techniques using polymerase chain reaction (PCR), the focus has turned towards using these markers for resolving questions of both short- and long-term evolution of human populations.

Despite the phenotypic variability in the expression of genes influencing the anthropometric and dermatoglyphic variables, such traits are polygenetically determined, involving more than just a few genes, and represent the genome to a certain degree. Furthermore, generation of these variables involves little cost in comparison to the generation of molecular genetic markers. However, the genetic basis of most quantitative traits is not precisely known, and their resolving power with regard to population structure is expected to be lower compared to hypervariable DNA markers, such as short tandem repeat (STR) loci. To the best of our knowledge, however, this has not been empirically tested in the context of microevolutionary studies. Therefore, it is necessary to assess the relative usefulness and/or congruence of quantitative traits vis-à-vis DNA markers in portraying patterns of population structure expected from ethnohistorical information. With this objective in mind, we made an attempt to generate molecular marker data as well as traditional quantitative biological data-anthropometry and dermatoglyphics - on the same set of subjects from eight endogamous subgroups of the Golla caste population of southern Andhra Pradesh in India. A paper based on the 13 STR loci among seven of these eight subgroups appears elsewhere in this issue (Reddy et al. 2001). In the paper presented below, we report the findings on patterns of quantitative variation based on anthropometry and dermatoglyphic vari- 
ables among the Golla subpopulations and attempt to study the degree of correspondence with the patterns based on the STR loci.

\section{Materials and Methods}

Population. The Gollas are the great pastoral caste of the Telugu people of Andhra Pradesh. Their traditional occupation has been tending sheep and cattle and selling milk, although many of them have now acquired lands and practice agriculture as well. The Gollas are distributed throughout Andhra Pradesh. People belonging to this tradition and occupation are also found in other parts of India in different linguistic and geographical areas. They are known by different names and probably have different origins.

Extensive interviews with the elders of this community suggest that there are 12 endogamous subcastes within Gollas, although Thurston (1909) noted only 9 such groups. This may be because the distributions of some of these subcastes are highly localized and may have escaped the attention of the ethnographer. However, we have encountered only 7 such groups in our exploratory survey in a large area, and none of the elders of this community could give a complete list of all 12 subcastes. Nonetheless, these people still retain their traditional patterns intact and maintain a high degree of endogamy within the subcastes. The exchange of mates between the Golla subcastes has just started, restricted only to the youngest generation, and is still found to be below $1 \%$, as revealed by preliminary investigations conducted during the collection of anthropometric measurements. As is the case in other traditional populations of southern India, Gollas prefer consanguineous marriages (Table 1) and village endogamy, with marriage contacts usually restricted to a small radius. Therefore, we confined our study to a

Table 1. The Subcastes of Gollas Studied, Number of Samples Collected, and Inbreeding Coefficients

\begin{tabular}{lcccc} 
Group & Abbreviation & $\begin{array}{c}\text { No. of } \\
\text { Villages }\end{array}$ & $\begin{array}{c}\text { Sample } \\
\text { Size }\end{array}$ & $\begin{array}{c}\text { Inbreeding } \\
\text { Coefficient }^{a}\end{array}$ \\
\hline Doddi & (DO) & 5 & 55 & 0.0247 \\
Erra & $(\mathrm{ER})$ & 3 & 50 & 0.0268 \\
Karnam (West) & $(\mathrm{KAW})$ & 7 & 59 & 0.0175 \\
Karnam (East) & $(\mathrm{KAE})$ & 1 & 27 & 0.0417 \\
Pokanati & $(\mathrm{PK})$ & 6 & 61 & 0.0354 \\
Puja & $(\mathrm{PU})$ & 2 & 22 & 0.0327 \\
Punugu & $(\mathrm{PN})$ & 4 & 49 & 0.0312 \\
Kurava & $(\mathrm{KU})$ & 2 & 11 & 0.0217 \\
\hline
\end{tabular}

a. Estimated on the basis of consanguinity status of the parents of the subjects in different subgroups. 
culturally homogeneous area called Chittoor district in Andhra Pradesh and collected samples from all subgroups found in that area. Each of the seven subcastes (Table 1) found in this area is distinguished by a unique variant of their traditional occupation, as well as by certain microcultural variation in the pattern of marriage ceremonies and dress patterns. Barring Thurston's (1909) ethnographic account, there is very little that can be drawn from literature on the ethnography and origin of these people. Information gathered from the Golla elders did not provide any clear answers, either.

Data and Sample. Anthropometric measurements and dermal prints were collected between May and July 1997. The anthropometrics and the finger and palm prints were collected from the same set of 334 adult males, sampled from 30 villages distributed in nine taluks of the Chittoor district in southern Andhra Pradesh (Figure 1). These subjects belonged to the seven subcastes. The names of the subcastes, number of villages from which samples were collected for each subcaste, and the group-wise sample sizes are furnished in Table 1, along with the average inbreeding coefficient estimated for each population based on the consanguinity

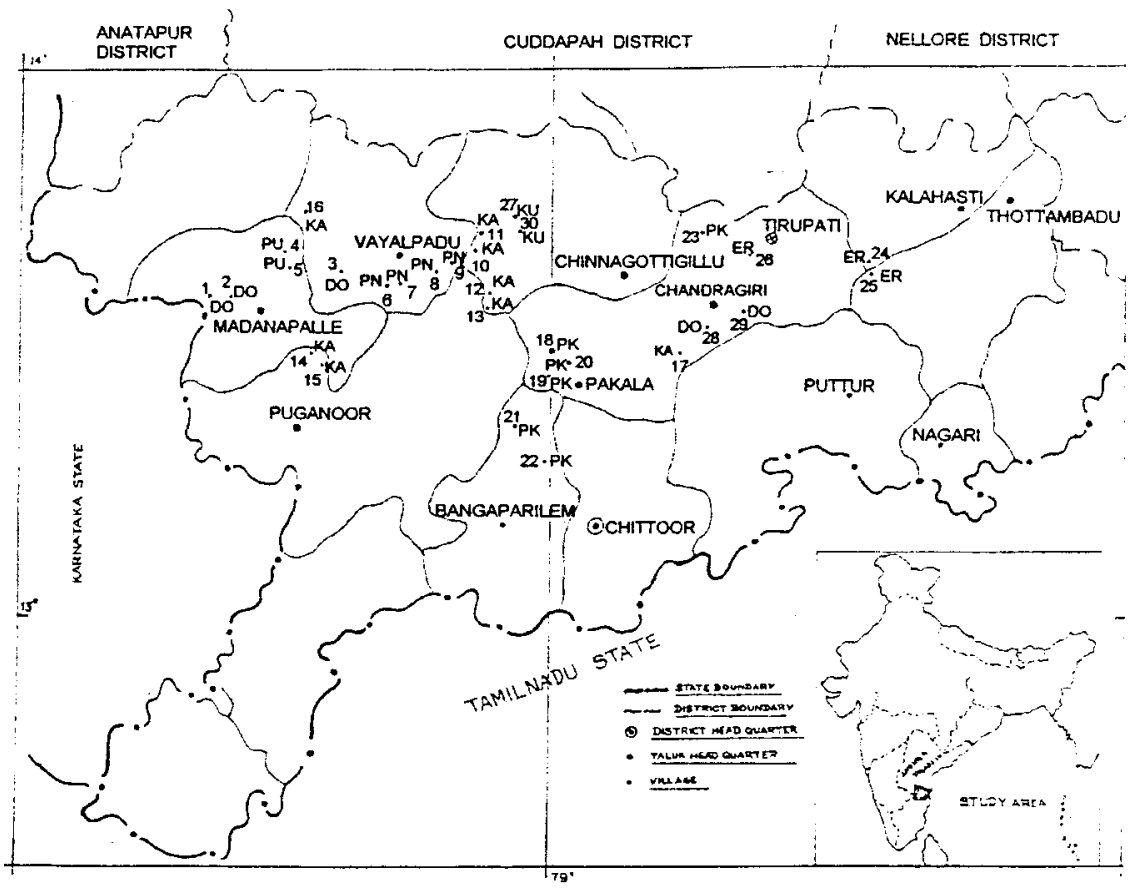

Figure 1. Map showing the location of the study area in Andhra Pradesh and the 30 villages from which the blood samples were collected. The village numbers and the abbreviated population names are given in the map. Explanations of the population abbreviations can be found in Table 1. 
of the parents of the subjects. One of the subcastes, Karnam, was found to be reproductively isolated and geographically separated, being distributed in western and eastern parts of the district, and was treated as two separate groups. Efforts were made to represent one subject from each surname, and to exclude close relatives from the sample.

The following 11 anthropometrics were taken on each of the 334 subjects: height (HT), sitting height (SHT), head length (HL), head breadth (HB), minimum frontal breadth (MFB), bizygomatic breadth (BZB), bigonial breadth (BGB), upper facial height (UFH), nasal height (NH), nasal breadth (NB), and head circumference (HC). The finger and palm prints collected on the same set of subjects, using the ink and roller method (Cummins and Midlo 1961), were scored for a number of finger and palmar quantitative and qualitative variables. However, only quantitative variables, 10 larger finger ridge counts, and the 10 palmar variables-namely, a-b, b-c, and c-d interdigital ridge counts, atd angle, and number of triradii on palm - on each hand were included in the present study.

Both univariate analysis of variance (ANOVA) and multiple discriminant analysis were employed in order to study patterns of anthropometric and dermatoglyphic variation. The relative extent of differentiation in the substructured Gollas, and the patterns of the gene flow into, and isolation of, different subpopulations were examined using $\boldsymbol{R}$-matrix analysis of quantitative variables (Relethford and Blangero 1990) implemented in the RMET program by Relethford. The degree of correspondence between the geographic, genetic, and different biological distance matrices was tested through Mantel correlation coefficients computed using the MANTEL program by Relethford.

\section{Results}

Univariate Analysis. The results from univariate ANOVA are presented in Table 2 for the anthropometrics and the three sets of quantitative dermatoglyphic variables. The $F$-values suggest that, except for HT, SHT, BZB, and BGB, the anthropometric variables reveal highly significant heterogeneity $(p<0.05)$ among the subpopulations. Four of the 10 finger ridge counts, and 6 of the 10 palmar variables also showed significant heterogeneity among Golla subpopulations.

Multivariate Analysis. Results of the multiple discriminant analysis of the different sets of data are presented in Tables 3 and 4. Wilks $\lambda$ and associated $F$ values (Table 3) suggest highly significant discrimination among the subpopulations based on anthropometric traits $(p<0.001)$. However, the discrimination based on dermatoglyphic variables is lower $(p<0.01)$, particularly when only finger ridge counts were used $(p>0.05)$. The palmar dermatoglyphic variables are much more discriminatory when compared to finger ridge counts. The eigenvalues and the percentage of variance explained (Table 4) by the three variates are highest for anthropometry, followed by those for the palmar variables. Stepwise 
$296 /$ reddy et al.

Table 2. Results of Univariate ANOVA for the Anthropometric and Quantitative Dermatoglyphic Variables among the Eight Subgroups of the Golla Caste

\begin{tabular}{|c|c|c|c|c|c|c|c|c|}
\hline \multirow[b]{2}{*}{ Variable } & \multicolumn{2}{|c|}{ Anthropometry } & \multicolumn{3}{|c|}{ Finger Ridge Counts (Larger) } & \multicolumn{3}{|c|}{ Quantitative Palmar Variables } \\
\hline & $F$-value & $p$ & Variable & $F$-value & $p$ & Variable & $F$-value & $p$ \\
\hline$\overline{\mathrm{HT}}$ & 0.76 & 0.625 & $\mathrm{RC} 1$ & 1.12 & 0.351 & $a-b R$ & 2.01 & 0.053 \\
\hline SHT & 1.09 & 0.369 & $\mathrm{RC} 2$ & 1.99 & 0.055 & $\mathrm{~b}-\mathrm{cR}$ & 3.06 & 0.004 \\
\hline $\mathrm{HL}$ & 4.78 & 0.000 & RC3 & 2.58 & 0.013 & $c-d R$ & 3.97 & 0.000 \\
\hline $\mathrm{HB}$ & 3.88 & 0.000 & $\mathrm{RC} 4$ & 2.80 & 0.008 & $\angle \mathrm{atdR}$ & 5.08 & 0.000 \\
\hline MFB & 2.71 & 0.010 & RC5 & 1.91 & 0.067 & TPR & 1.64 & 0.124 \\
\hline BZB & 1.90 & 0.069 & LC1 & 0.80 & 0.591 & $a-b L$ & 0.80 & 0.585 \\
\hline BGB & 1.74 & 0.100 & LC2 & 2.01 & 0.054 & b-cL & 2.15 & 0.038 \\
\hline UFH & 2.49 & 0.017 & LC3 & 2.11 & 0.042 & $\mathrm{c}-\mathrm{dL}$ & 5.20 & 0.000 \\
\hline $\mathrm{NH}$ & 2.06 & 0.047 & LC4 & 3.05 & 0.004 & $\angle$ atdL & 4.73 & 0.000 \\
\hline NB & 4.01 & 0.000 & LC5 & 2.02 & 0.052 & TPL & 1.18 & 0.313 \\
\hline $\mathrm{HC}$ & 4.14 & 0.000 & & & & & & \\
\hline
\end{tabular}

Degrees of freedom: 7, 326

Table 3. Multivariate Test Statistic, Wilks $\lambda$, and Associated $F$-value for the Extent of Differentiation Based on Different Sets of Quantitative Anthropometric and Dermatoglyphic Variables

\begin{tabular}{lccrc} 
Variable Set & Wilks $\lambda$ & F-value & $\begin{array}{c}\text { Degrees of } \\
\text { Freedom }\end{array}$ & $p$ \\
\hline Anthropometry & 0.460 & 3.42 & 77,1901 & 0.000 \\
Dermatoglyphs (all) & 0.489 & 1.66 & 140,2050 & 0.000 \\
Palmar variables & 0.638 & 2.12 & 70,1855 & 0.001 \\
Finger ridge counts & 0.772 & 1.20 & 70,1855 & 0.100 \\
\hline
\end{tabular}

discriminant analysis suggests that while 6 of the 11 anthropometric measurements ( $\mathrm{HC}, \mathrm{MFB}, \mathrm{BGB}, \mathrm{HB}, \mathrm{NB}$, and $\mathrm{NH}$ ) contribute significantly to the discrimination, only 6 of the 20 dermatoglyphic variables (LC4 and RC2 among finger and c-dL, $\angle$ atdL, b-cR and $\angle$ atdR among the palmar variables) are important contributors to the population discrimination.

This inference on the relative power of discrimination of different sets of variables is supported by the magnitude of $F_{S T}$ values obtained through the $\boldsymbol{R}$-matrix analysis (Table 5). The $F_{S T}$ value, which reflects the magnitude of the relative extent of intergroup differentiation, is largest in the case of the anthropometric variables (genetic $F_{S T}=0.0632$ ) and is at least double that observed for the dermatoglyphic variables, be it finger (0.0148), palmar (0.0370), or all the dermatoglyphic variables $(0.0273)$. Further, the intergroup differentiation in case of palmar variables is more than twice the value of the finger ridge counts.

The plots of group centroids on the two canonical variates suggest a clear 
Table 4. Eigenvalues and the Cumulative Proportion of Variation Explained by the Significant Canonical Variates in the Multiple Discriminant Analysis

\begin{tabular}{lcccc} 
Variable Set & $\begin{array}{c}\text { Canonical } \\
\text { Variate }\end{array}$ & Eigenvalue & $\begin{array}{c}\text { Proportion of } \\
\text { Variation }\end{array}$ & $\begin{array}{c}\text { Cumulative } \\
\text { Variation }\end{array}$ \\
\hline Anthropometry & 1 & 0.5238 & 0.578 & \\
& 2 & 0.2228 & 0.250 & 0.825 \\
Dermatoglyphs (all) & 3 & 0.0709 & 0.078 & 0.903 \\
& 1 & 0.2712 & 0.350 & \\
Palmar variables & 2 & 0.1646 & 0.212 & 0.562 \\
& 3 & 0.1466 & 0.189 & 0.751 \\
Finger ridge counts & 1 & 0.2016 & 0.421 & \\
& 3 & 0.1184 & 0.248 & 0.669 \\
& 1 & 0.0899 & 0.188 & 0.857 \\
& 2 & 0.0874 & 0.328 & \\
& 3 & 0.0724 & 0.271 & 0.599 \\
\end{tabular}

Table 5. Unbiased Estimates of $F_{S T} \pm$ SE Indicating the Extent of Discrimination Based on Different Sets of Variables

\begin{tabular}{llc} 
Variable Set & & $F_{S T} \pm S E$ \\
\hline Anthropometry & Minimum & $0.0282 \pm 0.0057$ \\
Dermatoglyphs (all) & Genetic $^{\mathrm{a}}$ & $0.0632 \pm 0.0072$ \\
& Minimum & $0.0091 \pm 0.0033$ \\
Finger RC & Genetic & $0.0273 \pm 0.0044$ \\
& Minimum & $0.0036 \pm 0.0041$ \\
Palmar dermatoglyphs & Genetic & $0.0148 \pm 0.0054$ \\
& Minimum & $0.0133 \pm 0.0052$ \\
& Genetic & $0.0370 \pm 0.0069$ \\
\hline
\end{tabular}

a. Genetic $F_{S T}$ s are obtained by using average $h^{2}$ as 0.540 for anthropometric measurements and 0.532 for dermatoglyphs. These values are appropriated to the present group of variables from the estimates of $h^{2}$ obtained for some fishermen populations of coastal Andhra Pradesh.

clustering of groups consistent with microgeographical affiliations in the case of the anthropometric traits (Figure 2). For example, Puja, Punugu, Doddi, and Karnam (West), who are distributed in the western parts of the district, form a close cluster, clearly separated from the eastern groups, namely, the Erra, Pokanati, and Karnam (East). Even the reproductive isolates of the same subcaste, Karnam, are clearly separated from each other, aligning with the geographically closer groups. The Kurava, whose position among the Golla is disputed, also lie, although not very distinctly, as an outlier. However, the group's geographical proximity to the western groups, particularly the Karnam (West), Punugu, and Puja, is reflected in the way it is placed in the multivariate space. 
Anthropometry

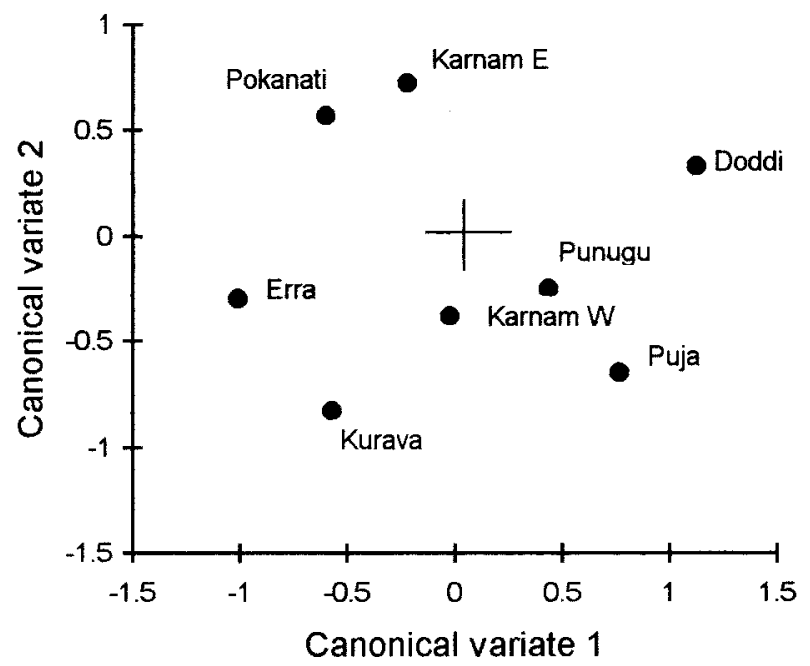

Figure 2. Plots of group centroids of the Golla subpopulations based on the multiple discriminant analysis of the 11 anthropometric variables.

While the separation between the eastern and western groups is basically on the second canonical variate, the western groups are dispersed on the first canonical variate. The plots of group centroids in the case of different sets of dermatoglyphic variables (Figure 3) portray a relatively less pronounced dispersion of groups in the multivariate space. Consistent with this is that the percentage of correct classification of the individuals into their respective groups, based on the discriminant functions, is generally low (Table 6), particularly for the dermatoglyphic variables. Even in the case of anthropometry, only about $36 \%$, on average, are correctly assigned to their respective groups, while the jackknifing procedure further reduces this figure to only about $27 \%$. The lack of differentiation is also apparent in the case of finger ridge counts, since the populations mostly lie around the centroid. That there is relatively greater congruence of anthropometric pattern with the geographic affiliation of the groups is illustrated by Mantel correlation (Table 7) for matrix correspondence. There is virtually no correspondence between the distance matrices of anthropometry on the one hand and of the different sets of dermatoglyphics on the other. Correlation between geographic distance matrix and different sets of dermatoglyphs is also weak and nonsignificant ( $p>$ $0.15)$. 
Dermatoglyphics

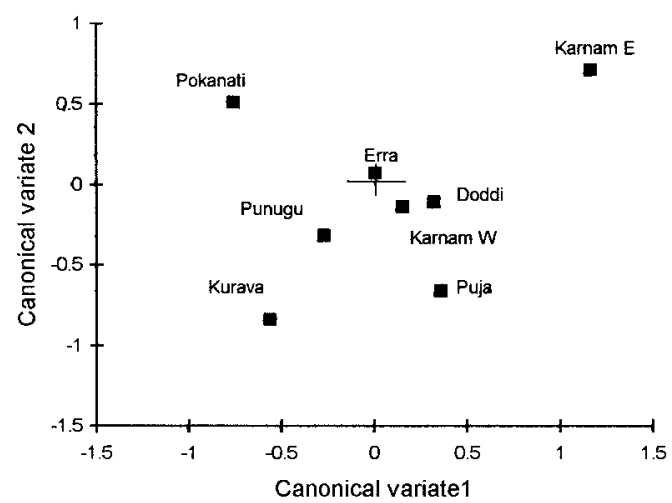

Finger

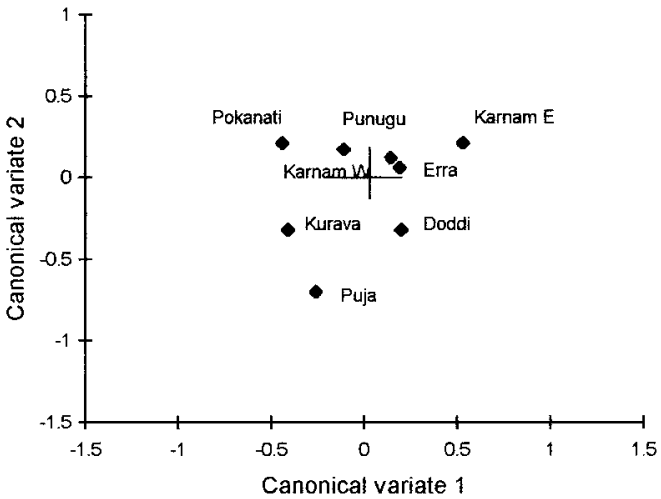

Palmar

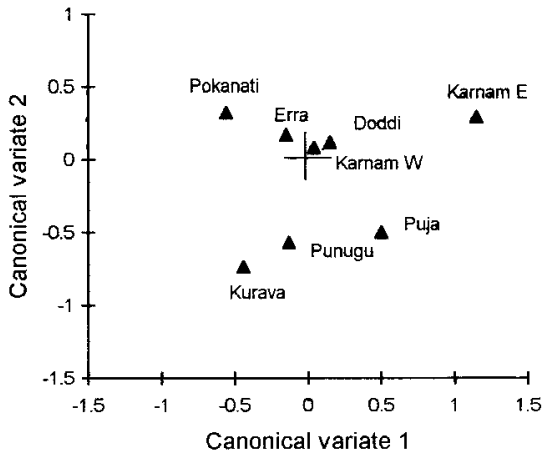

Figure 3. Plots of group centroids of the Golla subpopulations based on the discriminant analysis of the different sets of quantitative dermatoglyphic variables. 
Table 6. Percentage of Correct Classification of Individuals into Their Respective Groups, Based on Discriminant Functions Derived from Anthropometric Measurements and the Dermatoglyphs

\begin{tabular}{lcccc} 
Group & Anthropometry & $\begin{array}{c}\text { Finger Ridge } \\
\text { Counts }\end{array}$ & $\begin{array}{c}\text { Palmar } \\
\text { Variables }\end{array}$ & $\begin{array}{c}\text { All } \\
\text { Dermatoglyphs }\end{array}$ \\
\hline Doddi & 50.9 & 14.5 & 14.5 & 25.5 \\
Erra & 40.0 & 14.0 & 31.3 & 32.0 \\
Karnam (West) & 16.9 & 20.3 & 20.3 & 27.1 \\
Karnam (East) & 37.0 & 48.1 & 44.4 & 48.1 \\
Pokanati & 39.0 & 19.7 & 32.8 & 42.6 \\
Puja & 50.0 & 36.4 & 36.4 & 45.5 \\
Punugu & 24.5 & 8.2 & 26.5 & 26.5 \\
Kurava & 54.5 & 27.3 & 36.4 & 45.5 \\
Average & 36.2 & 20.1 & 28.1 & 33.8 \\
Jackknifed & 26.6 & 14.7 & 20.7 & 9.8 \\
\hline
\end{tabular}

Table 7. Matrix of Mantel Correlation Coefficients $(R)$ and the One-Tailed Probability (within Parentheses) between Distance Matrices Based on Different Sets of Variables

\begin{tabular}{lccccc} 
Distance Matrix & 1 & 2 & 3 & 4 & 5 \\
\hline Geography & - & & & \\
Anthropometry & $0.530(0.057)$ & - & - & \\
Dermatoglyphs & $0.244(0.186)$ & $0.018(0.501)$ & - & - & \\
Finger Ridge counts & $0.220(0.196)$ & $0.007(0.556)$ & $0.823(0.033)$ & - & \\
Palmar & $\quad 0.225(0.177)$ & $0.009(0.439)$ & $0.936(0.034)$ & $0.601(0.068)$ & - \\
\hline
\end{tabular}

R-Matrix Analysis and the Patterns of Gene Flow. According to the model of Harpending and Ward (1982), which was extended to quantitative variables by Relethford and Blangero (1990), the average heterozygosity of the $i^{\text {th }}$ population $\left(H_{i}\right)$ should be equal to the overall mean heterozygosity of the entire population, $H_{t}$ (in this case all Golla populations) multiplied by $\left(1-r_{i i}\right)$, where $r_{i i}$ is the genetic distance of a particular population from the centroid. If the gene flow from outside the cluster varies from population to population, this linear relationship no longer holds. Isolated populations will be less heterozygous than the linear prediction, whereas populations receiving more gene flow from outside the cluster will be more heterozygous. Thus, the theory indicates that we might gain some insights by examining the outliers.

According to ethnographic information (e.g., Thurston 1909) and from what we could gather from the elders of the Golla community, it is expected that Erra and Karnam present themselves above the regression line. This is because the Erra 
Golla are said to be a result of exogamous unions between Golla women and Brahmin men, and the Karnam were supposed to have admixed with an agricultural caste called Reddy, which has certain occupational similarities. The alien Kurava, whose position among the Golla is disputed, and who are considered a separate group outside the Golla, are expected to show relatively large centroid distance.

The regression plots of heterozygosity versus the centroid distance of the groups are given in Figure 4 for anthropometry, and in Figure 5 for different sets of dermatoglyphics. In general, the above expectations are not met given the way the populations are placed on the regression plots, except that the Erra are placed above the regression line in the case of finger ridge counts. The most consistent observation from these plots is the position of the alien Kurava as an outlier below the theoretical line, somewhat removed from the centroid. The position of Karnam (East), which is a small, highly inbred and isolated population, far removed from the centroid, may suggest relatively greater effect of the random genetic drift on this isolate. However, its position marginally above the expected regression line, given that the Karnam (West), placed below the line in close proximity to the centroid, is difficult to explain since no exogamous marriages were reported among them. Although Doddi lies above the expected regression line as a distinct outlier in the case of anthropometry, it is neither consistent with the expectations of gene flow nor is it similarly placed in the case of dermatoglyphic variables.

\section{Discussion}

The anthropometric variables suggest highly significant differentiation of the Golla subgroups as indicated by multiple discriminant analysis. The $F_{S T}$ value

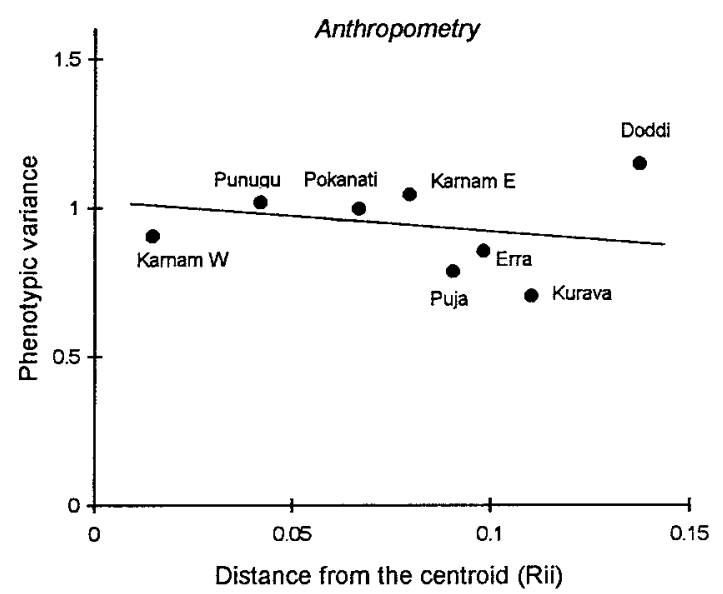

Figure 4. Plots of mean phenotypic variance versus the anthropometric distance from the centroid $\left(r_{i i}\right)$ of the Golla populations, and the theoretical regression line. 
Dermatoglyphics

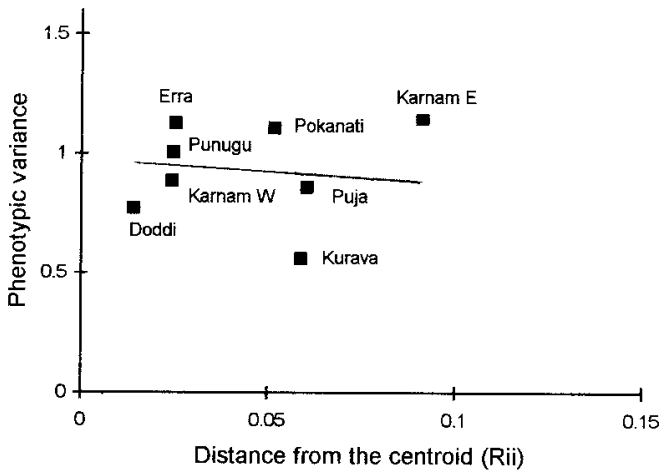

Finger

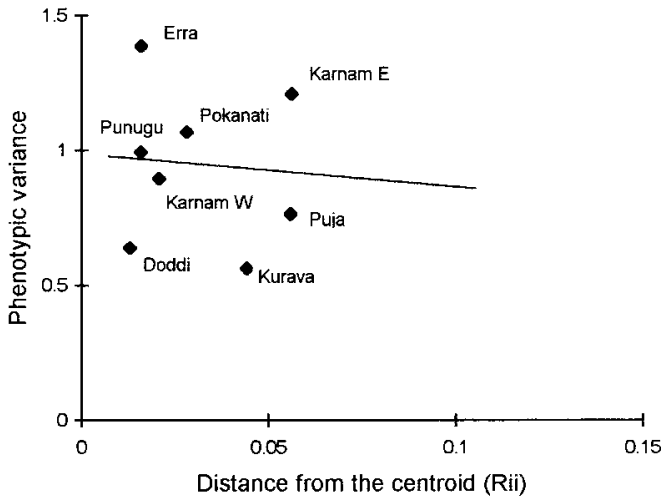

Palmar

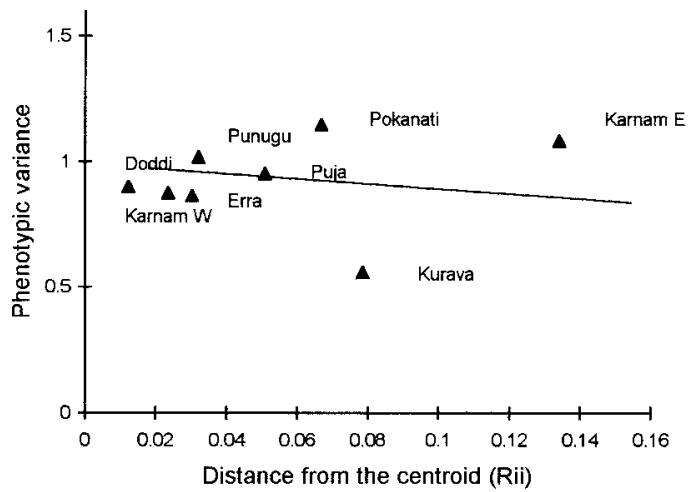

Figure 5. Plots of mean phenotypic variance versus the dermatoglyphic distance from the centroid $\left(r_{i i}\right)$ of the Golla populations, and the theoretical regression line, for different sets of dermatoglyphic variables. 
$(0.063 \pm 0.0072)$ derived through $\boldsymbol{R}$-matrix analysis is much larger than those observed for traditional genetic markers, as well as for microsatellite DNA markers among Indian populations with much higher levels of hierarchy. However, the proximity of the groups in the multivariate space is generally based on the microgeographic affiliations. By and large, while the groups inhabiting the western parts of the district are placed closely together, those from the eastern parts are relatively closer to each other (Figure 2). Given that the socioeconomic variation among the Golla subgroups is very limited, and that all of them are distributed in a culturally homogeneous and geographically delimited area, this observed pattern of population affinities cannot be considered as predominantly mediated by geographic or environmental factors, per se, but could be due to genetic similarity implicit in the history of formation of these groups.

The differentiation based on quantitative dermatoglyphics, particularly that based on the finger ridge counts, is relatively much smaller (Figure 3), and the population configurations are consistent with neither the geographic pattern nor with the known ethnohistorical affiliation of the groups. Although the discrimination based on palmar variables, and the discrimination when both finger and palmar variables were combined, was relatively greater compared to finger ridge counts alone, the patterns of population affinities still are not consistent with expectations based on either geographic or ethnohistorical grounds. Furthermore, the matrix correspondence between the anthropometric and dermatoglyphic distances is close to zero, as suggested by the Mantel correlations (Table 7). None of these distance matrices shows any correspondence with the distance matrix based on the STR loci.

Discordance in the pattern of population relationships based on dermatoglyphics and other biological variables, particularly serological and anthropometric, appears to be a rule rather than an exception (see Plato 1970; Chai 1972; Neel et al. 1974; Crawford et al. 1976; Jantz and Chopra 1983; Reddy et al. 1987; Reddy et al. 2000). Dermatoglyphic variables are considered to undergo slow rates of evolutionary change, hence are presumably less useful in depicting local level variations even at the level of different castes and tribes within a region (Rothhammer et al. 1977; Rudan 1978; Jantz and Hawkinson 1979; Froehlich and Giles 1981a, 1981b; Reddy and Reddy 1992). Krishnan and Reddy (1994) found the results of multivariate graphical analysis of the finger ridge counts of about 200 Indian populations consistent with this observation, since the population constellations in that study were based on major geographic and and/or ethnic criteria, while the local level variations are submerged. The close resemblance between Jewish populations of different countries after 2000 years of separation (Sachs and Bat-Miriam 1957) is a classic example of the temporal stability of dermatoglyphs. Given these observations, it is not surprising that the dermatoglyphic variables did not provide insights into the population structure of the subdivided Golla, with their relatively short history of separation among the constituent populations.

In the past, many processes were documented to be responsible for population subdivision within the Indian castes. Among those, geographic isolation, 
economic polarity, and exogamous marriages that occurred outside the traditional norms leading to excommunication of such couples from their respective castes are said to be most common. Some of these processes may be implicit in the patterns of population structure, and the $\boldsymbol{R}$-matrix analysis, particularly the regression of mean heterozygosity/phenotypic variance on the distance of populations from the centroid (Harpending and Ward 1982; Relethford and Blangero 1990), is supposed to offer useful insights in this regard. The above proponents of the model and many other later investigators (Devor et al. 1984; Relethford 1985; Jantz and Meadows 1995; Puppala and Crawford 1996; Reddy and Chopra 1999; Reddy et al. 2000) found encouraging results in their application of the model to several case studies involving local populations.

However, results of $\boldsymbol{R}$-matrix analysis, particularly the regression plots of phenotypic variance versus the distance from the centroid, are not generally consistent with expected patterns of gene flow into these groups with reference to anthropometry and different sets of dermatoglyphs. Further, the position of populations in the regression plot is discordant among different sets of variables, particularly between anthropometry and different sets of dermatoglyphs.

In conclusion, the analyses of dermatoglyphics and anthropometrics did not provide clear insights into population structure and history of differentiation of the Golla groups at the level of caste substructure, although earlier studies suggest the usefulness of dermatoglyphics, in particular, at higher levels of population hierarchy. The usefulness of anthropometrics in portraying broad ethnohistorical relationships at the higher levels of hierarchy is suspect, given that those variables are mediated by environmental factors in their manifestation. Nevertheless, the question that needs to be addressed is whether molecular genetic markers in general, and the 13 STR loci in particular that we studied among seven of these eight groups, are able to provide better insights into population substructure, especially at this level of population hierarchy. The answer seems to be yes. We have in another paper (Reddy et al. 2001, in this issue) concluded that the STR loci provide useful insights into the population structure and genetic microdifferentiation among the Golla subpopulations with a short evolutionary history. Not only is the distinctness of the alien Kurava, whose position among the Gollas is disputed, clearly depicted by their earlier divergence from the rest of Golla groups, but so is the sequence of differentiation among the remaining populations, in congruence with their known ethnohistorical backgrounds. Moreover, the patterns of external gene flow inferred from the regression plot are in concurrence with the known backgrounds of the groups.

Acknowledgments This work was done during B.M. Reddy's tenure as Fulbright visitor to the Laboratory of Biological Anthropology, University of Kansas, Lawrence, Kansas. He thanks the Fulbright Foundation for support. We thank colleagues and friends, in particular Professor P. Chengal Reddy and Dr. Venkatramana, at the Sri Venkateswara University, Tirupati, for cooperation during the fieldwork. Last, but not least, the coopera- 
tion and hospitality of the members of the Golla community during the fieldwork is gratefully appreciated. We thank the two anonymous reviewers for suggestions on the earlier version of this manuscript, which helped in improving presentation of the results.

Received 5 January 2000; revision received 1 June 2000.

\section{Literature Cited}

Basu, A. 1969. The Pahira: A population genetical study. Am. J. Phys. Anthropol. 31:399-416.

Chai, C.K. 1972. Biological distances between indigenous populations of Taiwan. In The Assessment of Population Affinities in Man, J.S. Weiner and J. Huizinga, eds. Oxford: Clarendon Press, 182-210.

Crawford, M.H., R. Lisker, and R.P. Briceno. 1976. Genetic differentiation of two Tlaxcaltecan populations. In The Tlaxcaltecans: Prehistory, Demography, Morphology and Genetics, M.H. Crawford, ed. Lawrence, KS: Department of Anthropology, University of Kansas, 169-175.

Cummins, H., and C. Midlo. 1961. Finger Prints, Palms and Soles. New York: Dover.

Devor, E.J., M.H. Crawford, and V. Bach-Enciso. 1984. Genetic population structure of the Black Caribs and Creoles. In Current Developments in Anthropological Genetics, Vol. 3, Black Caribs: A Case Study in Biocultural Adaptation. M.H. Crawford, ed. New York: Plenum Press, 365-380.

Froehlich, J.W., and E. Giles. 1981a. A multivariate approach to finger print variation in Papua New Guinea: Implications for prehistory. Am. J. Phys. Anthropol. 54:73-91.

Froehlich, J.W., and E. Giles. 1981b. A multivariate approach to finger print variation in Papua New Guinea: Perspectives on the evolutionary stability of the dermatoglyphic markers. Am.J. Phys. Anthropol. 54:93-106.

Harpending, H.C., and R. Ward. 1982. Chemical systematics and human evolution. In Biochemical Aspects of Evolutionary Biology, M. Nitecki, ed. Chicago: University of Chicago Press, 213-256.

Jantz, R.L., and V.P. Chopra. 1983. A comparison of dermatoglyphic methodologies in population studies. Am. J. Phys. Anthropol. 60:61-67.

Jantz, R.L., and C.H. Hawkinson. 1979. Finger ridge count variability in Sub-Saharan Africa. Ann. Hum. Biol. 6:41-53.

Jantz, R.L., and L. Meadows. 1995. Population structure of the Algonquian speakers. Hum. Biol. 67:375-386.

Karve, I., and K.C. Malhotra. 1968. Biological comparison of eight endogamous groups of the same rank. Curr. Anthropol. 9:109-124.

Krishnan, T., and B.M. Reddy. 1994. Geographical and ethnic variability of finger ridge counts: Biplots of male and female Indian samples. Ann. Hum. Biol. 21:155-169.

Malhotra, K.C. 1978a. Microevolutionary dynamics among the Govdas of Goa. In Evolutionary Models and Studies in Human Diversity, R.J. Meier et al., eds. The Hague, Netherlands: Mouton, 315-323.

Malhotra, K.C. 1978b. Founder effect, gene drift and natural selection among four nomadic mendelian isolates. In Evolutionary Models and Studies in Human Diversity, R.J. Meier et al., eds. The Hague, Netherlands: Mouton, 279-314.

Malhotra, K.C. 1979. Excommunication as a process leading to the formation of new groups. The Eastern Anthropologist 32:49-53.

Malhotra, K.C., R. Chakraborty, and A. Chakraborty. 1978. Gene differentiation among the Dhangar caste-cluster of Maharashtra, India. Human Heredity 28:26-36. 
Murty, J.S., B. Muralidhar, and J.D. Goud. 1993. Hierarchical gene diversity and genetic structure of tribal population of Andhra Pradesh, India. Am. J. Phys. Anthropol. 90:169-183.

Neel, J.V., F. Rothhammer, and J.C. Lingoes. 1974. The genetic structure of tribal population, the Yanomama Indians: X. Agreement between representatives of village distances based on different sets of characteristics. Am. J. Hum. Genet. 26:281-303.

Plato, C.C. 1970. Dermatoglyphics and flexion creases on the Cypriots. Am. J. Phys. Anthropol. 38:421-438.

Puppala, S., and M.H. Crawford. 1996. Genetic structure and phylogeny of populations of India: Andhra Pradesh. Homo 47:73-84.

Ramana, G.V., J.M. Naidu, and J.S. Murty. 1996. Genetic structure of the Manne Dora, a tribal population of Andhra Pradesh. Hum. Biol. 68:63-74.

Reddy, B.M. 1982. Population biology of the marine fishermen of Puri, Orissa, India. Ph.D. dissertation, University of Calcutta.

Reddy, B.M., and V.P. Chopra. 1999. Biological affinities between migrant and parental populations of fishermen on the east coast of India. Hum. Biol. 71:803-822.

Reddy, B.M., V.P. Chopra, B. Karmakar et al. 2000. Quantitative dermatoglyphics and population structure in Northwest India. Am. J. Hum. Biol. 12:315-326.

Reddy, B.M., V.P. Chopra, and D.P. Mukherjee. 1987. Biological affinities between the migrant groups of fishermen of Puri coast, India. Am. J. Phys. Anthropol. 74:407-416.

Reddy, B.M., V.P. Chopra, A. Rodewaldt et al. 1989. Genetic differentiation among some endogamous groups of fishermen of the eastern coast, India. Ann. Hum. Biol. 16: 321-333.

Reddy, B.M., V.P. Chopra, A. Rodewaldt et al. 1995. Genetic affinities between migrant and parental populations of fishermen on the east coast of India. Am. J. Hum. Biol. 7:51-63.

Reddy, B.M., and M. Gadgil. 1999. Dynamics of endogamy and resource utilization patterns among the marine fishermen castes of the Karnataka coast, India. (Unpublished manuscript.)

Reddy, B.M., and P.C. Reddy. 1992. Dermatoglyphic affinities among the Telugu Populations with contrasting ethnohistorical backgrounds. Am. J. Hum. Biol. 4:669-682.

Reddy, B.M., G. Sun, J.R. Luis et al. 2001. Genomic diversity at thirteen short tandem repeat loci in a substructured caste population, Golla, of southern Andhra Pradesh, India. Hum. Biol. 73:175190.

Relethford, J.H. 1985. Isolation by distance, linguistic similarity, and the genetic structure on Bougainville Island. Am. J. Phys. Anthropol. 66:317-326.

Relethford, J.H., and J. Blangero. 1990. Detection of differential gene flow from the patterns of quantitative variation. Hum. Biol. 62:5-25.

Rothhammer, F., R. Chakraborty, and E. Llop. 1977. A collation of gene and dermatoglyphic diversity at various levels of population differentiation. Am. J. Phys. Anthropol. 46:51-59.

Rudan, P. 1978. Biological structure of Istrian population-study of distances by anthropometric traits, dermatoglyphic properties and blood group gene frequency. Coll. Anthropol. 2:53-58.

Sachs, L., and M. Bat-Miriam. 1957. The genetics of Jewish populations in Israel. Am. J. Hum. Genet. 9:117-126.

Sirajuddin, S.M., R. Duggirala, and M.H. Crawford. 1994. Population structure of the Chenchu and other south Indian tribal groups: Relationship between genetic, anthropometric, dermatoglyphic, geographic and linguistic distances. Hum. Biol. 66:865-884.

Thurston, E. 1909. Castes and Tribes of Southern India. Vol. 2. C-J. Madras: Govt. Press, 284-295. 